\title{
Effect of Titanium on the Tensile Ductility of 30 mass\% Chromium Ferritic Steels*
}

\author{
Tadashi Fukuda \\ Institute for Materials Research, Tohoku University, Sendai 980-8577, Japan
}

The effect of titanium on the ductility of $30 \%$ chromium ferritic steels was investigated by tensile testing at low temperatures. Carbon content is $0.023 \pm 0.002$ mass $\%$. Titanium content is varied from 0.051 to 0.26 mass $\%$. The ratio of titanium content to carbon content, Ti/C, ranges from 2.1 to 12.4. Two kinds of heat treatment with or without solution treatment were adopted to obtain different types of morphology of carbide precipitates. Aging after solution treatment gives rise to grain boundary precipitation of coarse Cr carbides and numerous fine Ti carbides, depending on $\mathrm{Ti} / \mathrm{C}$ ratio, while annealing without solution treatment produces coarse globular carbide particles within the grains. The Effect of Ti/C ratio on the ductile-brittle transition temperature (DBTT) determined by the tensile tests is not as remarkable as that on the DBTT determined by Charpy impact tests. In the case of specimens containing globular carbide particles within the grains, there is no noticeable influence of varying $\mathrm{Ti} / \mathrm{C}$ ratio on fracture modes, while in the case of specimens containing grain boundary carbides, the effect of Ti/C ratio on fracture modes is remarkable and the amount of intergranular fracture first decreases with increasing Ti/C ratio up to 8 and then increases with the ratio at testing temperatures above $200 \mathrm{~K}$.

(Received December 16, 2004; Accepted March 29, 2005; Published May 15, 2005)

Keywords: high chromium ferritic steels, ductility, titanium carbides, morphology of carbides, ductile-brittle transition temperature, intergranular fracture

\section{Introduction}

In the previous papers, ${ }^{1-7)}$ the author reported that the amount of $\mathrm{Cr}$ carbide and $\mathrm{Cr}$ nitride precipitates has more important effects on mechanical properties than the amount of $\mathrm{C}$ and $\mathrm{N}$ contents in 30 mass\% $\mathrm{Cr}$ ferritic steels and reported that ductile-brittle transition temperatures (DBTTs) for reduction of area (RA) in tensile tests and the DBTT determined by Charpy impact tests depend on the volume and morphology (which means precipitation site, size, and shape) of $\mathrm{Cr}$ carbide, $\mathrm{Cr}$ nitride, and $\mathrm{Ti}$ carbide precipitates. That is, $\mathrm{Cr}$ carbide, $\mathrm{Cr}$ nitride, and $\mathrm{Ti}$ carbide precipitates at grain boundaries lead to more remarkable increase in the DBTT determined by tensile and impact tests than those precipitate particles within the grains. Fine spheroidal $\mathrm{Cr}$ carbide, $\mathrm{Cr}$ nitride, and Ti carbide particles within the grains do not exert a significant detrimental effect on the DBTT for RA. Furthermore the DBTT determined by the Charpy impact tests also remarkably depends on the ratio of Ti content to $\mathrm{C}$ content, $\mathrm{Ti} / \mathrm{C}$. ${ }^{8}$

The purpose of the present study is to clarify the effects of $\mathrm{Ti} / \mathrm{C}$ ratio on the DBTT for $\mathrm{RA}$ and tensile fracture mode, in the cases of specimens containing Ti carbide particles within the grains and grain boundary Ti carbide precipitates.

\section{Experimental Procedure}

Four $4 \mathrm{~kg}$ heats of $\mathrm{Fe}-30 \% \mathrm{Cr}$ alloys were melted from electrolytic iron and electrolytic chromium by a high frequency vacuum induction furnace. In order to obtain specimens containing different Ti contents, different amount of sponge titanium was added in the molten $\mathrm{Fe}-30 \% \mathrm{Cr}-$ $0.02 \% \mathrm{C}$ alloy after changing $\mathrm{Ar}$ into the furnace. The chemical compositions of as-cast specimens are given in

*This Paper was Originally Published in Japanese in J. Jpn. Inst. Met. 68 (2004) 134-137.
Table 1 Chemical composition of $\mathrm{Fe}-30 \% \mathrm{Cr}$ alloys (mass\%).

\begin{tabular}{ccccccc}
\hline & $\mathrm{Cr}$ & $\mathrm{C}$ & $\mathrm{N}$ & $\mathrm{O}$ & $\mathrm{Ti}$ & $\mathrm{Ti} / \mathrm{C}$ \\
\hline TC1 & 29.5 & 0.024 & 0.001 & 0.002 & 0.051 & 2.1 \\
\hline TC2 & 29.3 & 0.022 & 0.001 & 0.003 & 0.10 & 4.5 \\
\hline TC3 & 29.8 & 0.025 & 0.001 & 0.004 & 0.21 & 8.4 \\
\hline TC4 & 29.7 & 0.021 & 0.001 & 0.003 & 0.26 & 12.4 \\
\hline
\end{tabular}

Table 1. The content of $\mathrm{C}$ is $0.023 \pm 0.002$ mass $\%$. The content of Ti is varied from 0.051 to 0.26 mass $\%$. The ratio of $\mathrm{Ti} / \mathrm{C}$ ranges from 2.1 to 12.4 .

Cast round ingots of $55 \mathrm{~mm}$ in diameter were hot forged and hot rolled at $1273 \mathrm{~K}$ down to $7 \mathrm{~mm} \times 13 \mathrm{~mm}$ square bars, shaper-finished to $5 \mathrm{~mm}$ in thickness, and then cold rolled to $0.5 \mathrm{~mm}$ in thickness. Longitudinal tensile specimens having gage sections of $17 \mathrm{~mm}$ long by $3 \mathrm{~mm}$ wide by $0.5 \mathrm{~mm}$ thick were prepared.

Two kinds of heat treatment were selected to obtain different morphologies of carbide and nitride precipitates. ${ }^{8)}$ In the process "SA" (Solution treatment and Aging), cold rolled specimens were solution treated at $1423 \mathrm{~K}$ for $300 \mathrm{~s}$, quenched into iced water, and aged at $1123 \mathrm{~K}$ for $900 \mathrm{~s}$ followed by quenching into iced water. In the process " $\mathrm{A}$ " (Annealing), cold rolled specimens were annealed at $1123 \mathrm{~K}$ for $3.6 \mathrm{ks}$ without solution treatment at $1423 \mathrm{~K}$ and quenched into iced water.

Tensile tests were carried out at temperatures ranging from $4.2 \mathrm{~K}$ to room temperature $(\mathrm{RT})$ at a strain rate of $4.9 \times$ $10^{-4} \mathrm{~s}^{-1}$ using an Instron machine. Microstructures of specimens heat treated by the process SA or A were observed by means of optical microscopy and transmission electron microscopy (TEM). Thin foils for TEM observations were first mechanically polished to about $200 \mu \mathrm{m}$ thick and then electrolytically thinned at (273-278) K in a mixed solution of $20 \%$ perchloric acid and $80 \%$ ethanol. The fracture surfaces 


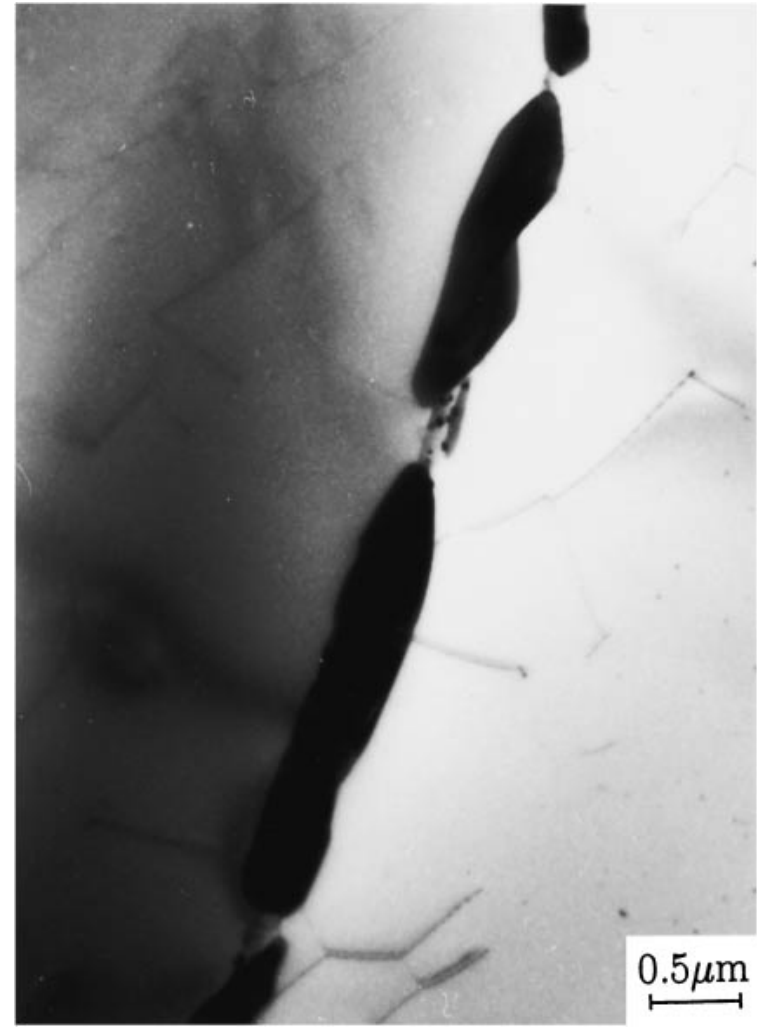

Fig. 1 Transmission electron micrograph of carbide precipitates in specimen $\mathrm{TC} 1(0.051 \% \mathrm{Ti})$, heat treated by the process SA.

after the tensile test were observed by means of a scanning electron microscope (SEM).

\section{Results}

\subsection{Microstructures}

When all of $\mathrm{C}$ atoms precipitate as $\mathrm{TiC}$, $\mathrm{Ti}$ content calculated is necessary 4 times $\mathrm{C}$ content. Figures 1 and 2 show typical electron micrographs of the carbide precipitates observed in the specimens $\mathrm{TC} 1(0.051 \% \mathrm{Ti}, \mathrm{Ti} / \mathrm{C}$ ratio below $4)$ and TC2 $(0.10 \% \mathrm{Ti}, \mathrm{Ti} / \mathrm{C}$ ratio above 4$)$ heat treated by the process SA, respectively. In the specimen TC1 $(0.051 \% \mathrm{Ti})$, coarse grain boundary carbides of $0.4 \mu \mathrm{m}$ wide and $2 \mu \mathrm{m}$ long are located discontinuously along the grain boundary (Fig. 1). The coarse grain boundary carbide is identified as $\mathrm{Cr}$ carbide consisting of $\mathrm{M}_{23} \mathrm{C}_{6}$ by analyses of electron diffraction pattern. Fine spheroidal precipitates are recognized between coarse grain boundary $\mathrm{Cr}$ carbides. The size of the fine precipitates is less than $0.05 \mu \mathrm{m}$. The composition of the fine precipitates may be considered as TiC. Electron diffraction patterns from upper and lower grains shown in Fig. 2 were analyzed as [113] and [111] reciprocal lattice planes. In the specimen TC2 (0.10\% Ti) (Fig. 2), numerous fine spheroidal $\mathrm{Ti}$ carbide precipitates in the $0.1 \mu \mathrm{m}$ size range are recognized at the grain boundary. The fine spheroidal grain boundary precipitates are considered as TiC since carbide precipitates which will be showed later in Fig. 4 are identified as $\mathrm{TiC}$ by the analyses of electron diffraction pattern. The morphology of Ti carbide precipitates in the specimens TC3 $(0.21 \% \mathrm{Ti})$ and TC4 $(0.26 \% \mathrm{Ti})$ heat treated by the process $\mathrm{SA}$, is similar to that in the

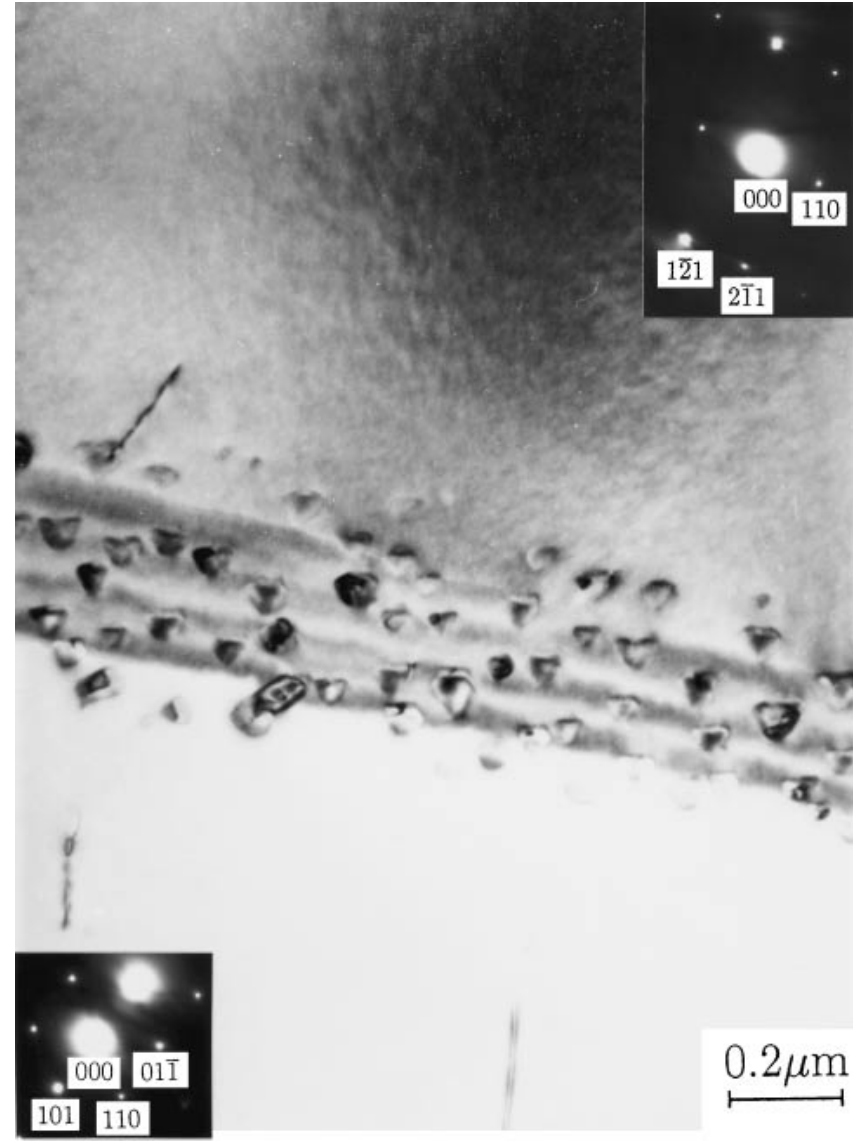

Fig. 2 Transmission electron micrograph of carbide precipitates in specimen TC2 $(0.10 \% \mathrm{Ti})$, heat treated by the process SA.

specimen TC2 $(0.10 \% \mathrm{Ti})$ heat treated by the process SA. In the case of the process $\mathrm{SA}$, the specimen with $\mathrm{Ti} / \mathrm{C}$ ratio of 2.1 contains coarse grain boundary $\mathrm{Cr}$ carbides and the specimens with $\mathrm{Ti} / \mathrm{C}$ ratio above 4.5 contain numerous fine spheroidal grain boundary Ti carbides.

Figures 3 and 4 show typical electron micrographs of the carbide precipitates observed in the specimens $\mathrm{TC} 1$ $(0.051 \% \mathrm{Ti})$ and $\mathrm{TC} 4(0.26 \% \mathrm{Ti})$ heat treated by the process A, respectively. In the specimen $\mathrm{TC} 1(0.051 \% \mathrm{Ti})$, coarse globular carbides are recognized within the grains (Fig. 3). The sizes of globular carbides are 0.5 to $2 \mu \mathrm{m}$. These carbides are identified as $\mathrm{Cr}$ carbide consisting of $\mathrm{M}_{23} \mathrm{C}_{6}$ by the analyses of electron diffraction pattern. In the specimen TC4 $(0.26 \% \mathrm{Ti})$, coarse globular carbides are recognized within the grains (Fig. 4). The sizes of globular carbides are 0.5 to $1 \mu \mathrm{m}$. These carbide precipitates are identified as Ti carbides consisting of $\mathrm{TiC}$ by the analyses of electron diffraction pattern. The morphology of $\mathrm{Ti}$ carbide particles in the specimens TC2 $(0.10 \% \mathrm{Ti})$ and TC3 $(0.21 \% \mathrm{Ti})$ heat treated by the process $\mathrm{A}$, is similar to that in the specimen TC4 $(0.26 \% \mathrm{Ti})$ heat treated by the process $\mathrm{A}$. In the case of the process $\mathrm{A}$, the specimen with $\mathrm{Ti} / \mathrm{C}$ ratio of 2.1 contains coarse $\mathrm{Cr}$ carbide particles within the grains and the specimens with $\mathrm{Ti} / \mathrm{C}$ ratio above 4.5 contain coarse $\mathrm{Ti}$ carbide particles within the grains.

Grain size measurement of the specimens after two heat treatment processes was carried out on the etched specimens. The grain sizes of the specimens TC1, TC2, TC3, and TC4 


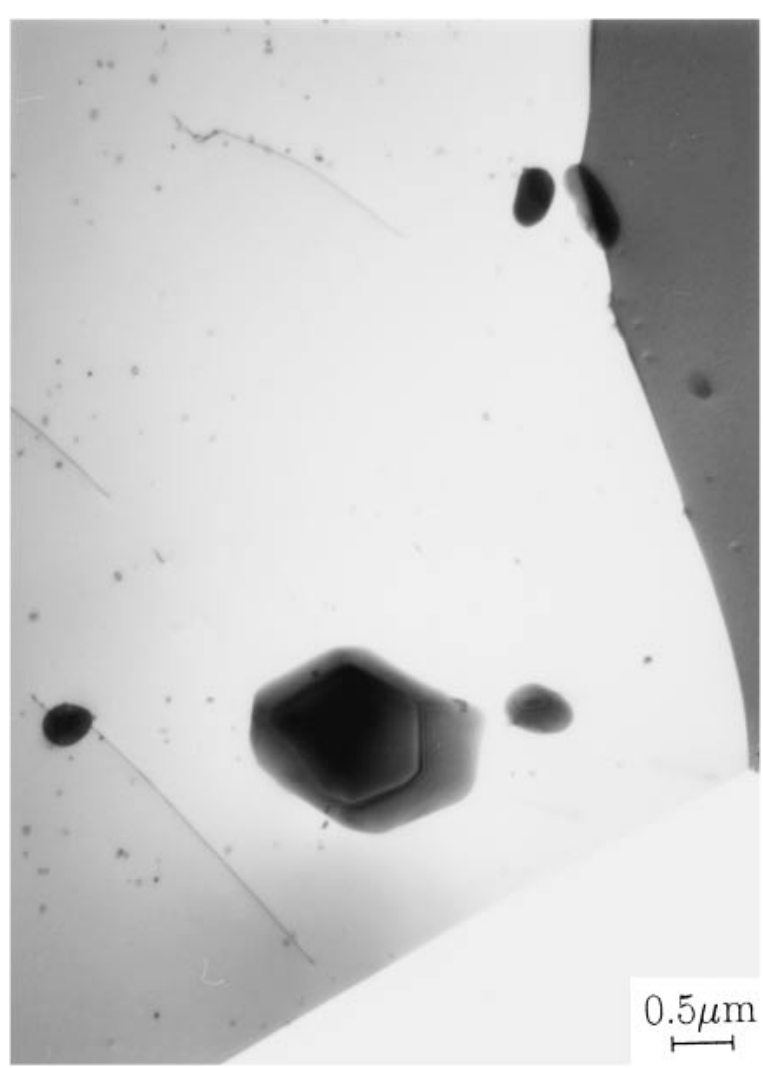

Fig. 3 Transmission electron micrograph of carbide precipitates in specimen $\mathrm{TC} 1(0.051 \% \mathrm{Ti})$, heat treated by the process $\mathrm{A}$.

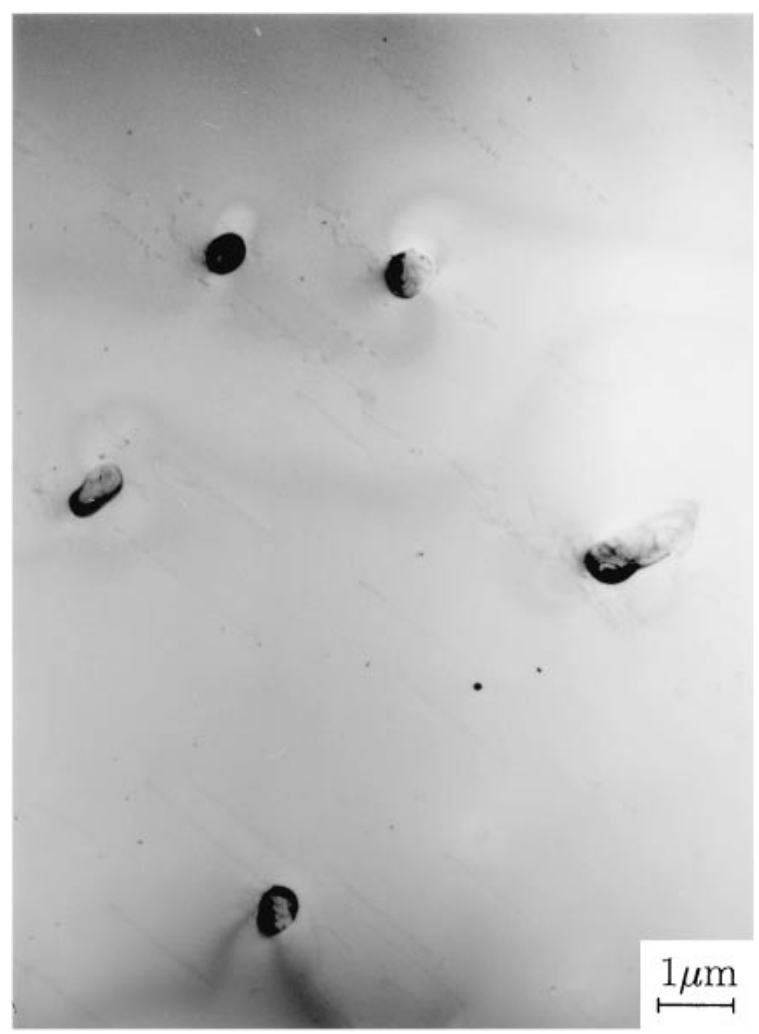

Fig. 4 Transmission electron micrograph of carbide precipitates in specimen TC4 $(0.26 \% \mathrm{Ti})$, heat treated by the process $\mathrm{A}$. heat treated by the process SA are 125 to $151 \mu \mathrm{m}$. The grain sizes of the specimens TC1, TC2, TC3, and TC4 heat treated by the process A are 20 to $28 \mu \mathrm{m}$. The grain size of the specimens heat treated by the process SA is larger than that of the specimens heat treated by the process $\mathrm{A}$.

\subsection{Tensile tests}

The values of the lower yield stress at RT ( $298 \mathrm{~K})$ of the specimens TC1, TC2, TC 3 , and TC4 heat treated by the process SA are 250 to $263 \mathrm{MPa}$ and the specimen TC4 $(0.26 \% \mathrm{Ti})$ indicates highest lower yield stress. In the specimens TC1, TC2, TC3, and TC4 heat treated by the process A, the lower yield stress of the specimen with $0.051 \% \mathrm{Ti}$ at RT is $292 \mathrm{MPa}$ and the lower yield stress of the specimens with above $0.1 \% \mathrm{Ti}$ increases from 271 to $280 \mathrm{MPa}$ with increasing Ti content. The yield stress of the specimens heat treated by the process SA is lower than that of the specimens heat treated by the process $\mathrm{A}$.

Figures 5 and 6 illustrate the change in RA of the specimens TC1 $(0.051 \% \mathrm{Ti})$ and TC3 $(0.21 \% \mathrm{Ti})$ in the tensile test conducted at temperatures ranging from $4.2 \mathrm{~K}$ to $\mathrm{RT}$, respectively. Microfractographic examinations were carried out on the fractured specimens. The DBTT was defined at the point where RA was equal to one-half of the upper shelf in RA. Marks D, B, and IG in Figs. 5 and 6 denote that fracture appearance is principally of dimple fracture-type (D), of brittle fracture-type (B) such as cleavage and quasi-cleavage fracture, and of intergranular fracture-type (IG), respectively. D-IG indicates the coexistence of dimple-type and intergranular-type. Similarly, the coexistence of brittle-type and intergranular-type is represented by B-IG. The number prior to IG indicates the ratio of intergranular fracture to total fracture area. The accuracy of the determination was $\pm 5 \%$.

In the specimen $\mathrm{TC} 1(0.051 \% \mathrm{Ti})$ heat treated by the process A (open double circles in Fig. 5), the RAs remain unchanged at $90 \%$ in the temperatures between RT and $153 \mathrm{~K}$, and then rapidly decrease with decreasing testing temperature. On the other hand, in the specimen TC1 $(0.051 \% \mathrm{Ti})$ heat treated by the process SA (open diamonds in Fig. 5), the RA starts to decrease at higher temperature with decreasing testing temperature. The DBTT for the specimen TC1 $(0.051 \% \mathrm{Ti})$ heat treated by the process $\mathrm{SA}$ is higher than that for specimen $\mathrm{TC} 1(0.051 \% \mathrm{Ti})$ heat treated by the process $\mathrm{A}$.

In the specimen $\mathrm{TC} 1(0.051 \% \mathrm{Ti})$ heat treated by the process $\mathrm{A}$, the fracture modes at testing temperatures above $153 \mathrm{~K}$ are of typical dimple-type and those at testing temperatures below $77 \mathrm{~K}$ are of brittle fracture. On the other hand, in the specimen TC1 $(0.051 \% \mathrm{Ti})$ heat treated by the process SA, the fracture mode at RT is of dimple fracture containing ductile intergranular fracture $(\mathrm{DIG})^{5)}$ and that at $200 \mathrm{~K}$ is of ductile intergranular fracture containing dimple. The fracture mode at $153 \mathrm{~K}$ is of brittle fracrure containing brittle intergranular fracture $(\mathrm{BIG})^{5)}$ and that at $77 \mathrm{~K}$ is of brittle fracture containing a small part of still brittler intergranular fracture.

After the heat treatment processes SA and A, the RA for the specimen TC3 $(0.21 \% \mathrm{Ti})$ (Fig. 6) shows similar behavior to that for specimen TC1 (0.051\% Ti) (Fig. 5).

The fracture mode of the specimen TC3 $(0.21 \% \mathrm{Ti})$ heat 


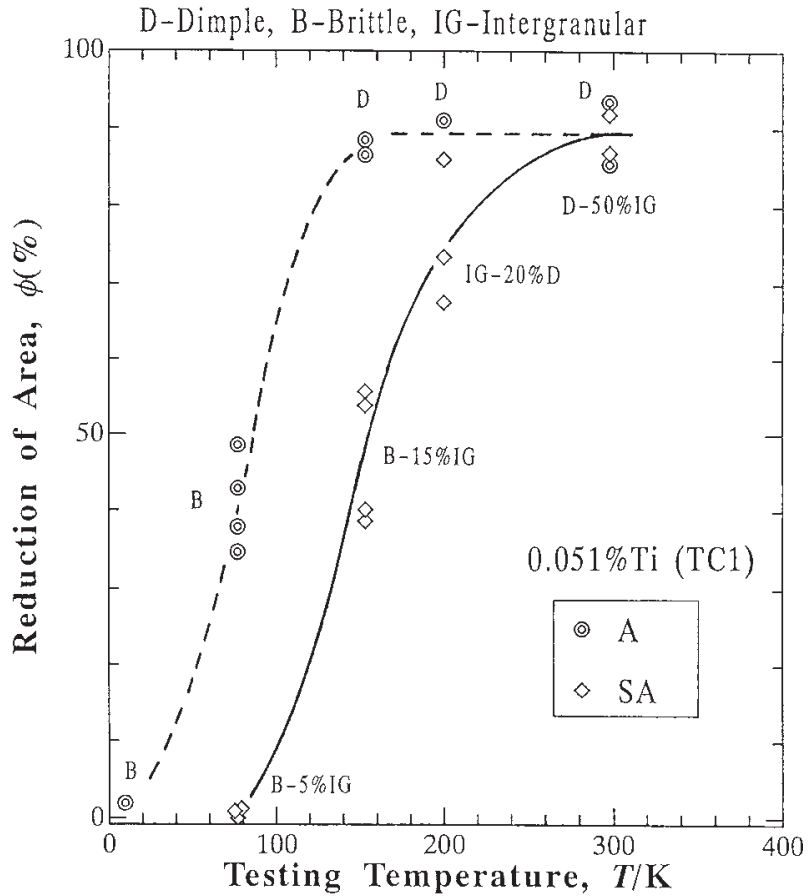

Fig. 5 Relation between reduction of area and testing temperature for specimens TC1 $(0.051 \% \mathrm{Ti})$, heat treated by the processes SA or A.

D-Dimple, B-Brittle, IG-Intergranular

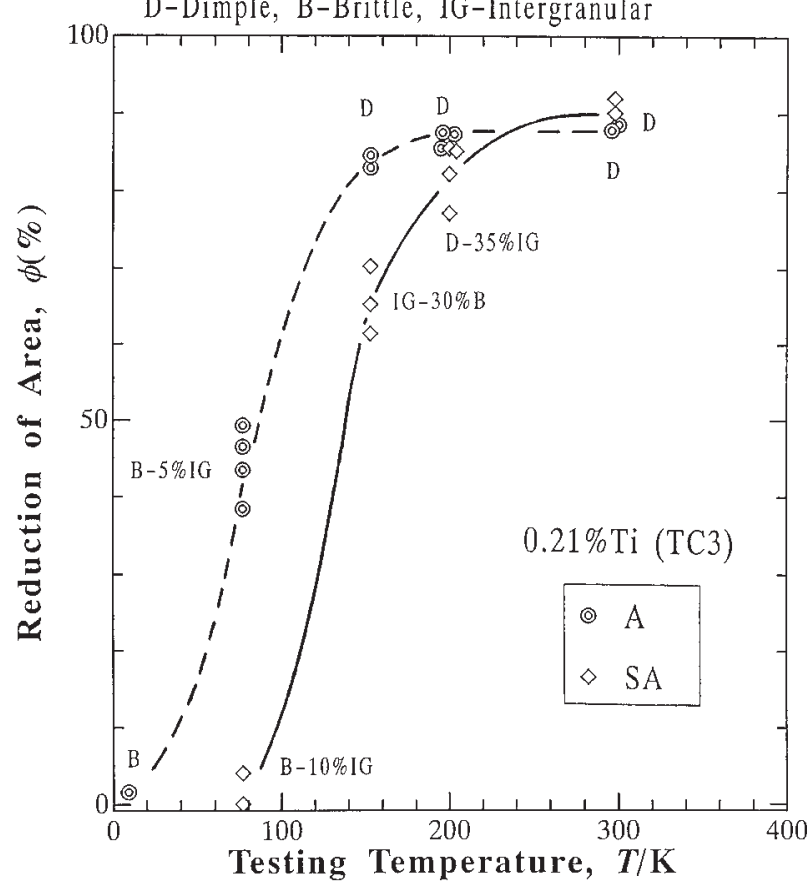

Fig. 6 Relation between reduction of area and testing temperature for specimens TC3 $(0.21 \% \mathrm{Ti})$, heat treated by the processes SA or A.

treated by the process A shows similar behavior to that for specimen TC1 $(0.051 \% \mathrm{Ti})$ heat treated by the process A. On the other hand, the fracture mode of the specimen TC3 $(0.21 \% \mathrm{Ti})$ heat treated by the process $\mathrm{SA}$ is remarkably different from that for specimen TC1 $(0.051 \% \mathrm{Ti})$ heat treated by the process SA. That is, the amount of ductile intergranular fracture for the specimen TC3 $(0.21 \% \mathrm{Ti})$ is smaller than that of ductile intergranular fracture for the specimen

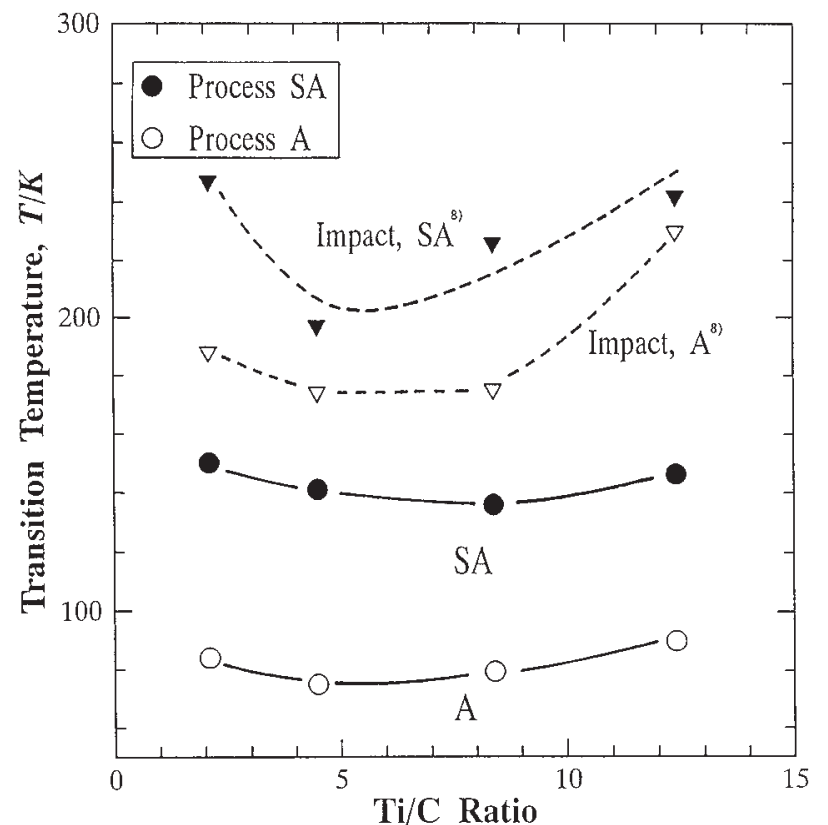

Fig. 7 Relation between $\mathrm{Ti} / \mathrm{C}$ ratio and ductile-brittle transition temperature in $\mathrm{Fe}-30 \% \mathrm{Cr}-\mathrm{C}-\mathrm{Ti}$ alloys, heat treated by the processes $\mathrm{SA}$ or $\mathrm{A}$. The broken lines in higher part of the figure show the results of ductilebrittle transition temperature determined by Charpy impact test for heat treatments of the processes SA and A. ${ }^{8)}$

TC1 (0.051\% Ti) at testing temperatures above $200 \mathrm{~K}$. However, at $153 \mathrm{~K}$, the amount of intergranular fracture for the former is larger than that for the latter. In the former specimen, ductile intergranular fracture, brittle intergranular fracture, and brittle fracture coexist at $153 \mathrm{~K}$, while in the latter specimen, brittle intergranular fracture and brittle fracture coexist at $153 \mathrm{~K}$.

Figure 7 shows the relation between the DBTT and Ti/C ratio in a series of $\mathrm{Ti}$ containing alloys. The broken lines in higher part of Fig. 7 show the results of the DBTT determined by Charpy impact tests for the specimens after the heat treatment processes SA and A. ${ }^{8)}$ The DBTTs in tensile tests for the specimens heat treated by the process SA are higher than those for the specimens heat treated by the process A. Both the DBTTs first slightly decrease with increasing $\mathrm{Ti} / \mathrm{C}$ ratio and then slightly increase with the ratio. The dependence of $\mathrm{Ti} / \mathrm{C}$ ratio for the DBTT in tensile tests is not more remarkable than that for the DBTT determined by Charpy impact testing. ${ }^{8)}$ It is considered that the unnoticeable dependence of $\mathrm{Ti} / \mathrm{C}$ ratio on the DBTT in tensile tests is due to the differences of strain rate, stress condition, and test piece size. ${ }^{9)}$

Figure 8 shows the relation between the amount of intergranular fracture and $\mathrm{Ti} / \mathrm{C}$ ratio in a series of $\mathrm{Ti}$ containing alloys. In the case of the process A (open symbol), there is no noticeable influence of varying $\mathrm{Ti} / \mathrm{C}$ ratio on the amount of intergranular fracture at testing temperatures above $153 \mathrm{~K}$. On the other hand, in the case of the process SA (solid symbol), the amount of intergranular fracture is remarkably affected by $\mathrm{Ti} / \mathrm{C}$ ratio. The amount of intergranular fracture at testing temperatures above $200 \mathrm{~K}$ is remarkably different from that at $153 \mathrm{~K}$. That is, at testing temperatures above $200 \mathrm{~K}$, the amount of intergranular 


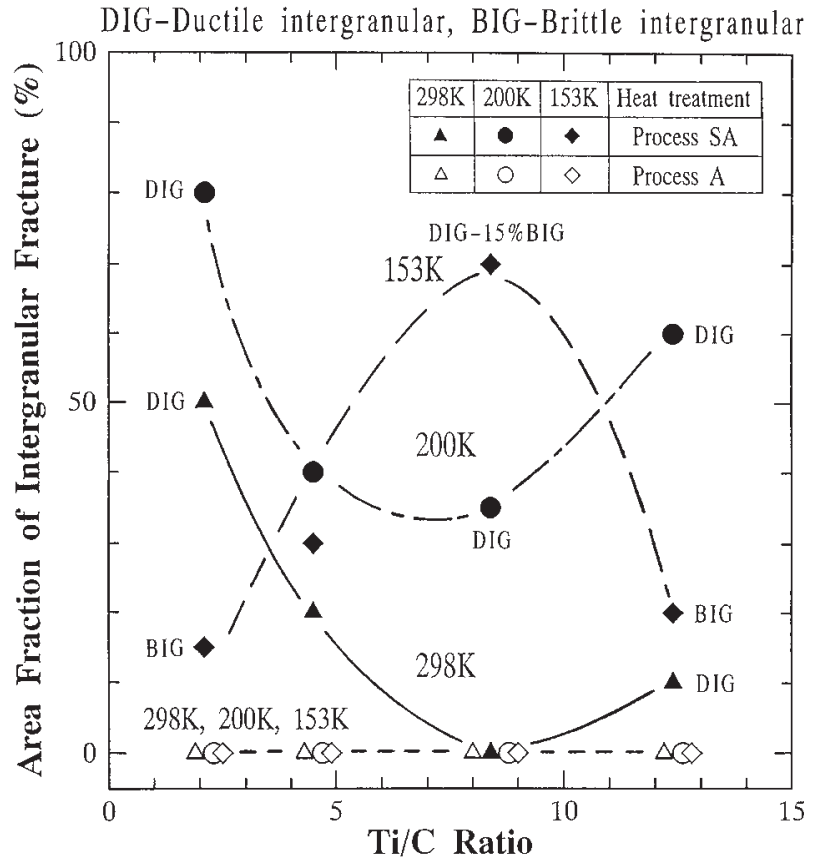

Fig. 8 Relation between $\mathrm{Ti} / \mathrm{C}$ ratio and area fraction of intergranular fracture in $\mathrm{Fe}-30 \% \mathrm{Cr}-\mathrm{C}-\mathrm{Ti}$ alloys, heat treated by the processes $\mathrm{SA}$ or A. Fractured at room temperature $(298 \mathrm{~K}), 200 \mathrm{~K}$, and $153 \mathrm{~K}$.

fracture coexisting dimple first decreases with increasing Ti/ $\mathrm{C}$ ratio up to 8 and then increases with increasing the ratio, however, at $153 \mathrm{~K}$, the amount of intergranular fracture coexisting brittle fracture is first increases with increasing $\mathrm{Ti} /$ $\mathrm{C}$ ratio up to 8 and then decreases with the ratio.

\section{Discussion}

In the present study, the effect of $\mathrm{Ti} / \mathrm{C}$ ratio on the fracture mode is remarkable. The intergranular fracture mechanism in the case of the process SA is discussed on the basis of the following two assumptions: (1) the intergranular fracture may be caused by the decohesion at the interfaces between the matrix and carbide precipitates at grain boundaries and (2) the area of the decohesion depends on the size of the grain boundary carbide precipitate. In the case of the specimens containing the grain boundary carbide precipitates, the amount of intergranular fracture first decreases with increasing $\mathrm{Ti} / \mathrm{C}$ ratio up to 8 and then increases with the ratio at testing temperatures above $200 \mathrm{~K}$ (Fig. 8). The grain boundary precipitate of the specimen with $\mathrm{Ti} / \mathrm{C}$ ratio of 2.1 is coarser than that of the specimens with above $\mathrm{Ti} / \mathrm{C}$ ratio of 4.5. Hence, the amount of intergranular fracture of the specimen with $\mathrm{Ti} / \mathrm{C}$ ratio of 2.1 is larger than that of the specimens with $\mathrm{Ti} / \mathrm{C}$ ratio of 4.5 and 8.4. For a large amount of the intergranular fracture of the specimen with $\mathrm{Ti} / \mathrm{C}$ ratio of 2.1 , the previous assumptions give a consistent full explanation. However, in the specimen with $\mathrm{Ti} / \mathrm{C}$ ratio of 12.4 which contains numerous fine grain boundary $\mathrm{Ti}$ carbides, this mechanism becomes inconsistent.

The amount of intergranular fracture takes a maximum at 8 of the ratio at $153 \mathrm{~K}$. The behavior at $153 \mathrm{~K}$ is considerably different from that at $200 \mathrm{~K}$ as shown in Fig. 8. At $200 \mathrm{~K}$, ductile intergranular fracture and dimple fracture coexist. At $153 \mathrm{~K}$, in the specimens with minimum and maximum ratio of $\mathrm{Ti} / \mathrm{C}$, brittle intergranular fracture and brittle fracture coexist, whereas in the specimen with $\mathrm{Ti} / \mathrm{C}$ ratio of 8.4 , ductile intergranular fracture, brittle intergranular fracture, and brittle fracture coexist. The specimen with $\mathrm{Ti} / \mathrm{C}$ ratio of 8.4 contains the smallest amount of brittle fracture at $153 \mathrm{~K}$. Therefore, at $153 \mathrm{~K}$, the specimens with minimum and maximum ratio of $\mathrm{Ti} / \mathrm{C}$ may more early cause brittle intergranular fracture than the specimen with $\mathrm{Ti} / \mathrm{C}$ ratio of 8.4 since initiation of microcracks for brittle fracture is considered to be caused by the brittle intergranular fracture.

\section{Conclusions}

The effect of titanium on the ductility of $30 \% \mathrm{Cr}$ ferritic steels was investigated by tensile testing at low temperatures. The content of $\mathrm{C}$ is $0.023 \pm 0.002$ mass $\%$. The content of $\mathrm{Ti}$ is varied from 0.051 to 0.26 mass $\%$. The ratio of $\mathrm{Ti} / \mathrm{C}$ ranges from 2.1 to 12.4 . Ductility was evaluated by the DBTT in reduction of area and fracture modes. The results obtained are summarized as follows:

(1) Aging after solution treatment gives rise to grain boundary precipitation of coarse $\mathrm{Cr}$ carbides at $\mathrm{Ti} / \mathrm{C}$ ratio of 2.1 and numerous fine $\mathrm{Ti}$ carbides at $\mathrm{Ti} / \mathrm{C}$ ratio above 4.5. Annealing without solution treatment produces coarse globular carbide particles within the grains.

(2) The effect of $\mathrm{Ti} / \mathrm{C}$ ratio on the DBTT is slight.

(3) The effect of $\mathrm{Ti} / \mathrm{C}$ ratio on fracture modes of the specimens containing grain boundary carbides is more remarkable than that on fracture modes of the specimens containing carbide particles within the grains. In the case of the specimens containing the morphology of grain boundary carbides, the amount of intergranular fracture first decreases with increasing $\mathrm{Ti} / \mathrm{C}$ ratio up to 8 and then increases with the ratio at testing temperatures above $200 \mathrm{~K}$, while at $153 \mathrm{~K}$ it first increases with increasing $\mathrm{Ti} / \mathrm{C}$ ratio up to 8 and then decreases with the ratio.

\section{Acknowledgments}

The author wishes to thank their colleagues at Technical Services Division of Institute for Materials Research, Tohoku University, for their experimental cooperation.

\section{REFERENCES}

1) T. Fukuda, Y. Kataura and T. Ototani: J. Jpn. Inst. Met. 54 (1990) 93100.

2) T. Fukuda, H. Suenaga and M. Tanino: J. Jpn. Inst. Met. 59 (1995) 437446.

3) T. Fukuda: J. Jpn. Inst. Met. 63 (1999) 581-584.

4) T. Fukuda: J. Jpn. Inst. Met. 63 (1999) 1137-1140.

5) T. Fukuda and M. Tanino: Mater. Trans., JIM 40 (1999) 1396-1401.

6) T. Fukuda: J. Jpn. Inst. Met. 65 (2001) 151-154.

7) T. Fukuda: J. Jpn. Inst. Met. 67 (2003) 165-168.

8) T. Fukuda: J. Jpn. Inst. Met. 67 (2003) 590-594.

9) R. A. Lula: Met. Prog. 110 (1976) 24-29. 